\title{
Ablation Properties of C Fibers and SiC Fibers Reinforced Glass Ceramic Matrix Composites upon Oxyacetylene Torch Exposure
}

\author{
Julien Beaudet ${ }^{1}$, Jonathan Cormier ${ }^{1}$, André Dragon¹, Magali Rollin², Guillaume Benoit ${ }^{1}$ \\ ${ }^{1}$ Institut Pprime, Centre National de la Recherche Scientifique, Ecole Nationale Supérieure de Mécanique et d'Aérotechnique, \\ Université de Poitiers, Département Physique et Mécanique des Matériaux, ENSMA, Futuroscope Chasseneuil, France; ${ }^{2}$ Pyromeral \\ Systems S.A., Barbery, France. \\ Email: julien.beaudet@ensma.fr
}

Received August 16 ${ }^{\text {th }}, 2011$; revised August $26^{\text {th }}, 2011$; accepted September $3^{\text {rd }}, 2011$.

\begin{abstract}
The ablation properties of two laminated composites, having both a glass ceramic matrix and different kinds of fibers $(C$ or $\mathrm{SiC}$ ) with the same architecture, are evaluated and compared. Ablation tests are performed using an oxyacetylene torch on samples having two different thicknesses. Mass loss and ablation depth are measured after flame exposure. The results obtained show that the decomposition of SiC fibers during thermal exposure has a significant impact on ablation behavior. Oxidation of $\mathrm{SiC}$ produces a liquid $\mathrm{SiO}_{2}$ film at the top of the material during ablation. This leads to an improved ablation resistance compared to the glass ceramic matrix/C composite, especially in case of successive flame exposures where the $\mathrm{SiO}_{2}$ film consumes a substantial fraction of the heat flow during its liquefaction upon re-heating.
\end{abstract}

Keywords: Fiber, Ablation, High-Temperature Properties

\section{Introduction}

Ceramic matrix composites are widely used for many engineering applications concerning severe loading conditions including ballistic context or re-entry of space vehicles. For such applications, the material degradation mainly results from aerodynamic impact involving intense mechanical and thermal loading. Thermal protection is an essential factor of structural integrity for a spacecraft vehicle during re-entry phase. High thermal resistance of the corresponding material is required against short intense thermal and mechanical load.

Moreover, regarding flying structures, one of the primary design criteria is the mass gain. In this respect, increasing ablation resistance for protective structures of limited mass is an obvious technical challenge for spacecraft-related research and development [1].

In this context, strong research effort has been devoted to the study of ablative materials [2-5]. In conjunction with the mass gain imperative, the thermal protection systems employing composite materials have been developed. One feature of technological advances has been a substitution of polymer ablators (resol phenolic com- posites) by Ceramic Matrix Composite (CMC) ablators (having high thermal resistance). In such a way, Ceramic Matrix Composite (CMC) ablators have been introduced as coating protection materials and their thermal behavior has been extensively studied [1]. However, in addition to their relatively high cost, one of the major problems of the $\mathrm{CMC} /$ carbon based protection systems is their poor oxidative behavior: under exposure to a hot oxidative gas, a notable bulk material mass loss is observed due to chemical reactions with oxygen and water vapour. These phenomena have been reported by many authors [6-10] and more reliable carbon based systems have been searched for.

Chen et al. report on the ablation properties of carbon matrix reinforced carbon composite $(\mathrm{C} / \mathrm{C})$ exposed to oxygen/ethanol hot combustion mixture [2]. In the context termed "thermo-chemical ablation" by the authors, ablation rate is increasing with the Oxygen/Ethanol ratio. Chen et al. [9] examine ablated $\mathrm{C} / \mathrm{SiC}$ samples after oxyacetylene torch exposure. Scanning electron microscope (SEM) observations indicated white $\mathrm{SiO}_{2}$ dross produced by chemical recombination and oxidation of $\mathrm{SiC}$ in the ablated area. Several other authors [7] pointed 
out the generation of new specific microstructures during ablation processes. However, scarce work is available on the ablation performance correlated with the above mentioned observations.

During the last decade, the requirements for composites having the same (or closely same) high temperature mechanical performances under fire exposure and with a low environmental impact during the elaboration process, lead to the development of composites with ceramic matrix derived from geopolymer systems. Few authors have investigated the fire behavior of this new category of high performance composite $[11,12]$ with specific high temperature tests.

In the present work, the ablative properties of two composites with the same glass ceramic matrix are studied and an approach is attempted to show the advantages of a SiC Reinforced Composite (SiRC) compared to a Carbon Reinforced Composite (CRC). The corresponding specimens are exposed to oxyacetylene flame. Weight loss and ablation depth are measured after each test. SEM observations provide indications regarding the kinetics of material degradation. The ablation test results are finally analyzed as a function of the thermal loading, and degradation mechanisms are proposed.

To our best knowledge, this is the first time that glass ceramic composites derived from geopolymer systems are characterized under very high temperature ablative conditions.

\section{Experiments}

\subsection{Specimen}

Two kinds of composite materials are tested. The first one (denoted as SiRC in the following of the artcile) is reinforced by silicon carbide fibers while the other one (denoted as CRC) is reinforced by carbon fibers. Both have a glass ceramic matrix. Samples were supplied by PYROMERAL SYSTEMS SA, in the form of $50 \times 50$ $\mathrm{mm}^{2}$ plates with different thicknesses: $5 \mathrm{~mm}$ for CRC (PyroKarb ${ }^{\circledR}$ family), 2.5 and $5 \mathrm{~mm}$ for $\operatorname{SiRC}\left(\right.$ PyroSic ${ }^{\circledR}$ family).

Specimens are 2D laminated twill woven. The Pyro$\mathrm{Sic}{ }^{\circledR}$ composite $(\mathrm{SiRC})$ is a silicon-carbide-fiber-reinforced glass ceramic composite, with a $42 \%$ fiber volumetric ratio and $12 \%$ porosity. It has been developed for thermostructural applications at temperature up to $1000^{\circ} \mathrm{C}$ [13].

The PyroKarb ${ }^{\circledR}$ composite (CRC) is a carbon-fiberreinforced glass ceramic composite, with a $47 \%$ fiber volumic ratio and $23 \%$ porosity. It has been developed for thermostructural applications at temperature up to $500^{\circ} \mathrm{C}$.

The matrix of these composites is a glass ceramic in the system $\mathrm{K}_{2} \mathrm{O}-\mathrm{SiO}_{2}$. It is obtained by impregnating the fiber with an inorganic polymer. During the thermoseting, a 3D-network of oxide molecules is formed. The final composition and microstructure of the glass ceramic matrix is obtained from an adapted thermal treatment.

\subsection{Characterization}

Thermogravimetric analysis (TGA) was performed using a TA Instruments SDT 2960 device. The temperature was varied from ambient to $1200^{\circ} \mathrm{C}$ under air using a heating rate of $10^{\circ} \mathrm{C} \cdot \mathrm{min}^{-1}$.

The morphology and microstructure of samples before and after ablation tests were examined by scanning electron microscopy (SEM) using a JEOL 6100 microscope. Both transverse sections and top (i.e. normal to the ablated surface) views were used to characterize the sample microstructures after ablation exposure. Optimal SEM operating conditions were obtained using an acceleratory tension in the range $5 \mathrm{kV}-12 \mathrm{kV}$, depending on the sample type.

\subsection{Ablation Conditions}

The ablation tests were performed using an oxyacetylene torch based on the ASTM E 285-80 standard. This kind of test is widely used for the characterization of the ablation resistance of materials $[5,9,10,14,15]$. An air tight box was designed specifically for experiments. An electric linear actuator was used to move the sample under the flame. Sapphire glasses allowed measuring the temperature of the in-ablation surface using dual wavelength pyrometer during tests. This kind of radiometer takes into account the emissivity modification of the material during ablative exposure. The rear face temperature was measured with a K Type (chromel-alumel) thermocouple. Signals were recorded by an analogic acquisition card and transferred to a computer.

The torch was a blowpipe FAREL O/Si with an exhaust diameter of $1.1 \mathrm{~mm}\left(\mathrm{n}^{\circ} 4\right)$. Pressure levels of $\mathrm{O}_{2}$ and $\mathrm{C}_{2} \mathrm{H}_{2}$ were respectively set to 2 and 0.25 bar. The corresponding flow rates were $355 \mathrm{nl} \cdot \mathrm{h}^{-1}\left(\mathrm{O}_{2}\right)$ and $125 \mathrm{nl} \cdot \mathrm{h}^{-1}$ $\left(\mathrm{C}_{2} \mathrm{H}_{2}\right)$. This set-up produces approximately a $3300 \mathrm{~K}$ oxidative flame at the nozzle tip and a maximum heat flow of $5.40 \times 10^{6} \mathrm{~W} \cdot \mathrm{m}^{-2}$ at the sample surface.

An example of the surface temperature evolution recorded during a $30 \mathrm{~s}$ exposure at maximum heat flow is presented in Figure 1. It is observed that the surface temperature remains almost constant within a 2350 $2500 \mathrm{~K}$ range once the maximum temperature is reached.

Two kinds of ablation tests were performed: either simple exposure (SE) where ablation time varied from 2 to $30 \mathrm{~s}$ or multi-exposure (ME) where the exposure se- 


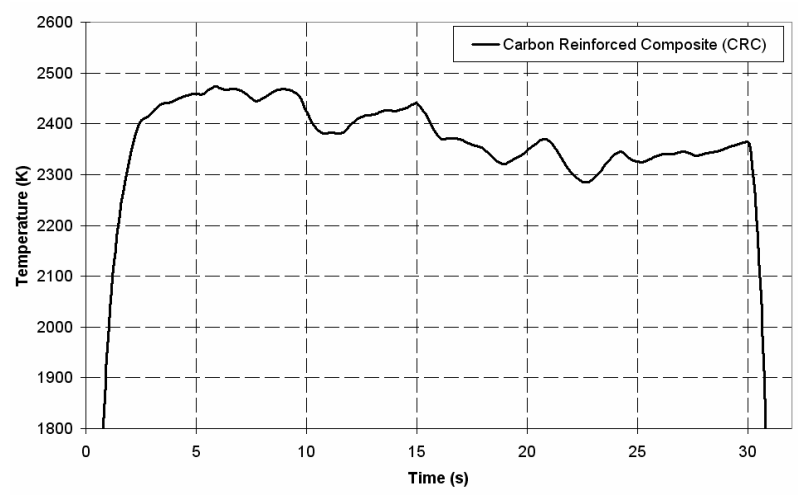

Figure 1. Surface temperature recording for a $30 \mathrm{~s}$ ablation test of a CRC composite.

quence was split into two or more events for a fixed total time. The total time was set to $20 \mathrm{~s}$ while the cooling time is set to 1 minute between each exposure. The tested sequences were: $2 \times 5 \mathrm{~s}+10 \mathrm{~s}, 2 \times 10 \mathrm{~s}$ and $15 \mathrm{~s}+5 \mathrm{~s}$.

The surface degradation was also recorded during ablation tests using a high resolution camera and specific filters to avoid any damage of the CCD camera due to high radiation of the in-ablation surface.

After ablation exposure, samples were analyzed as follows:

- Mass of the sample was measured with a digital balance whose resolution is $\pm 0.5 \times 10^{-4} \mathrm{~g}$ and compared to its initial mass before ablation.

- Ablation depth was evaluated by a mechanical pointer whose resolution is $1 \mu \mathrm{m}$. The difference between the initial surface height and the bottom of the ablated area was systematically quantified

These two quantitative criteria account for volumetric and surface ablation [15] respectively.

\section{Results}

\subsection{TGA Experiments}

Figure 2 plots the mass evolution relative to the initial mass (i.e. actual mass/initial mass) as a function of temperature. A progressive and limited (1\% at the maximum) mass loss is observed until a plateau is reached at approximately $750 \mathrm{~K}$ for both materials. Afterwards, a mass gain is observed until $1473 \mathrm{~K}$.

Both materials exhibit the same TGA behavior except in the last part of the curve (i.e. for a temperature over $1300 \mathrm{~K}$ ) where the mass gain is more pronounced for the SiRC.

Figure 2 shows that a mass gain is observed for both materials in the temperature range $700-1470 \mathrm{~K}$. For temperature lower than in the ablation tests, the two composites exhibit the same behavior.

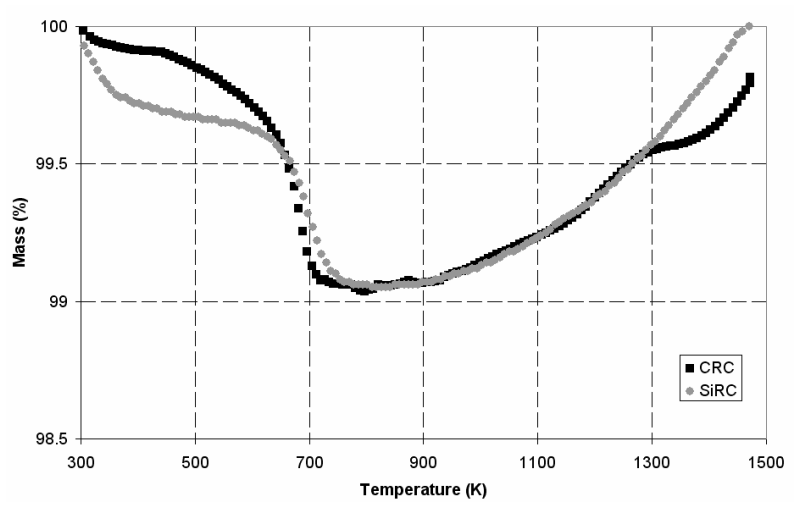

Figure 2. TGA curve for SiRC and CRC under air atmosphere.

\subsection{Ablation Tests}

Figures 3 and $\mathbf{4}$ present the mass loss and the maximum ablation depth as a function of ablation time after each Simple Exposure (SE) at a surface temperature of $\approx 2500$ $\mathrm{K}$ for $5 \mathrm{~mm}$ thick samples.

For each material, the mass loss follows a linear evolution between 5 and $30 \mathrm{~s}$ (Figure 3). The CRC appears to be more sensitive to mass loss compared to SiRC for the same ablation conditions: the mass loss rate is clearly higher for the carbon reinforced composite. The respective values are $2 \times 10^{-3} \mathrm{~g} \cdot \mathrm{s}^{-1}$ for SiRC compared to $1.5 \times$ $10^{-2} \mathrm{~g} \cdot \mathrm{s}^{-1}$ for CRC. The degradation rate is thus nearly 10 times greater for the CRC.

For example, after $10 \mathrm{~s}$, CRC looses approximately $0.15 \mathrm{~g}$ and for the SiRC, the weight loss is $0.025 \mathrm{~g}$. After $25 \mathrm{~s}$ the gap between the corresponding weight losses increases.

After evaluating the weight loss, the ablation depth is checked: the corresponding results are shown in Figure 4. As for weight loss, the variation of ablation depth is linear with respect to time for the two composites (from 5 to $45 \mathrm{~s}$ ). The CRC has approximately $40 \%$ deeper ablation compared to SiRC. Erosion rates are respectively $4 \times 10^{-2}$ $\mathrm{mm} \cdot \mathrm{s}^{-1}$ and $7 \times 10^{-2} \mathrm{~mm} \cdot \mathrm{s}^{-1}$ for SiRC and CRC composites.

The SiRC exhibits better ablation properties than CRC, both in terms of mass loss and ablation depth. For similar fiber architecture and matrix, the $\mathrm{SiC}$ reinforcement offers better resistance to high temperature exposure than $\mathrm{C}$ reinforcement under ablation conditions with an oxyacetylene torch.

\subsection{Ablation Microstructures}

Figure 5 presents SEM microstructures for both materials after a $20 \mathrm{~s} / 2500 \mathrm{~K}$ exposure. The SiRC bulk appears to be more porous than the CRC. The proportion of ma- 


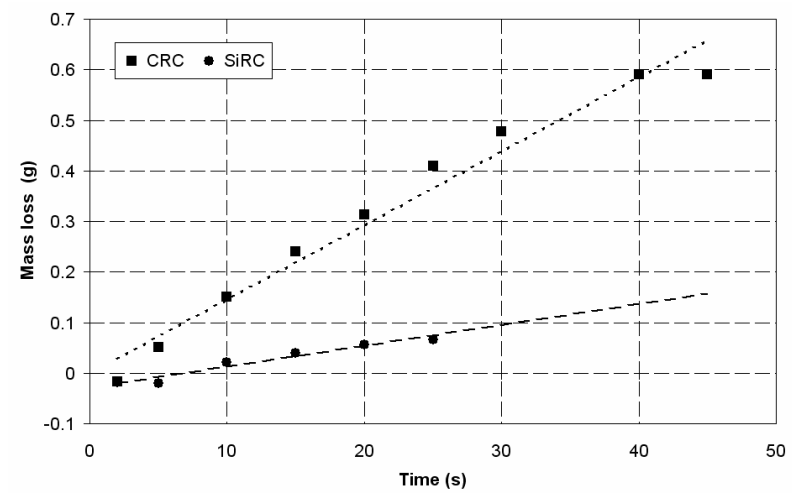

Figure 3. Mass loss versus ablation time for "single" exposure for $5 \mathrm{~mm}$ samples.

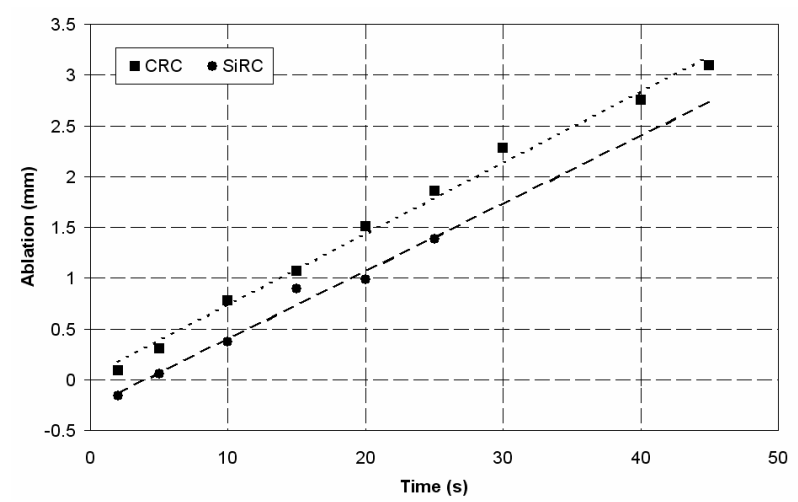

Figure 4. Ablation depth versus ablation time for $5 \mathrm{~mm}$ samples.

trix in the heat affected zone is clearly different from the virgin material for the SiRC composite. Delamination is apparent in this area for SiRC and glass is formed in the center of the ablation region. It is supposed that the liquefied matrix has risen up by a capillarity mechanism to the top of the material.

In summary, SiRC seems to be more affected by volumetric ablation compared to $\mathrm{CRC}$; the latter has a lower porosity compared to SiRC.

Figure 5 also reveals droplets at the top of the CRC material. It is not the same glass structure as that observed for the SiRC composite but it seems likewise to be composed of glass. In fact, EDX measurements (not presented in this article) revealed that those droplets are mainly composed of Silicon and Oxygen. These droplets arise from the thermo-oxidation of the glass ceramic matrix.

Videos recording during ablation highlight the very different ablative behavior of the materials. Some snapshots taken from the ablation video recording are presented in Figure 6. It is observed in Figures 6(a), 6(c) that the two composites have very different ablation be-
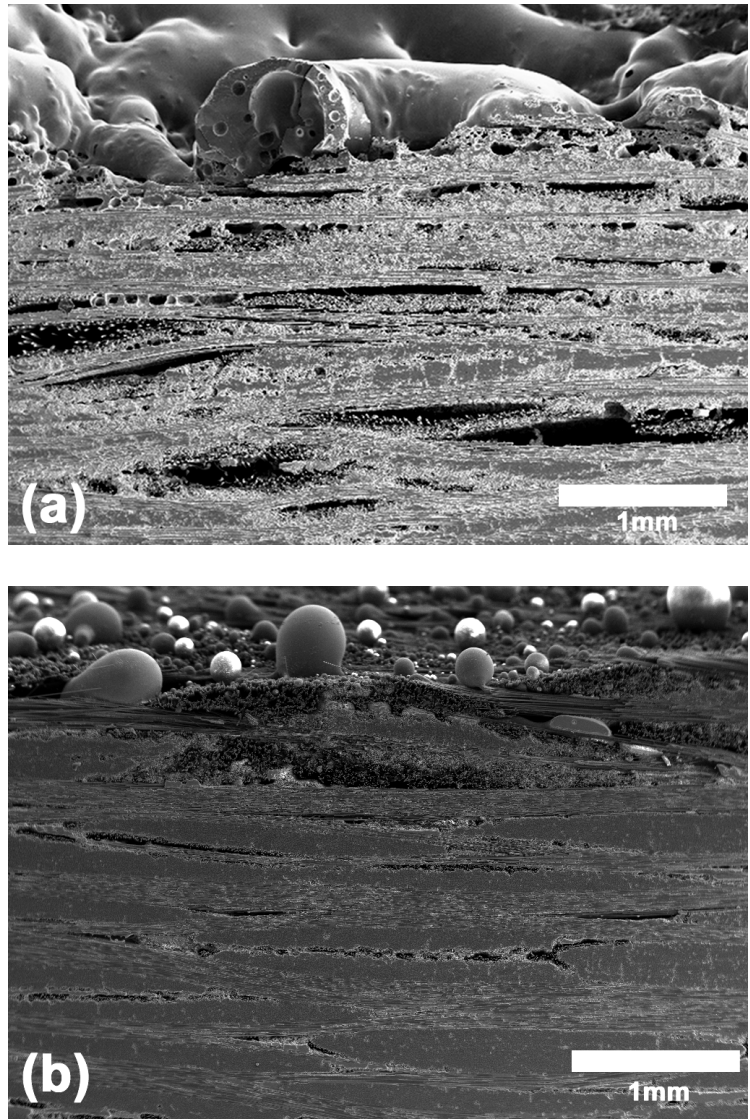

Figure 5. Cross section microstructures of SiRC (a) and CRC (b) after single $20 \mathrm{~s}$ exposure at $2500 \mathrm{~K}$.

havior in the very first moments $(1-2 \mathrm{~s})$ of ablation exposure. The SiRC melts with bubble formation whereas the CRC seems to volatilize accompanied with the formation of droplets.

These marked differences between CRC and SiRC during ablation reside in the occurrence of bubbles and the liquid material in the centre of ablation during fire exposition for the SiRC.

When increasing the ablation time, no liquid phase is observed at the CRC surface while the SiRC surface appears as a boiling liquid as seen in Figures 6(b) and 6(d). These observations confirm the presence of a liquid film at the surface of material during ablation.

\subsection{Influence of Thickness on Ablation Properties of SiRC}

The ablation resistance of the CRC is mainly controlled by the thermo-oxidation rate of the fibers and of the matrix while ablation resistance of SiRC is controlled by more complex state transformations which will be discussed in Section 4.

In his numerical study, Staggs [16] reports that the ab- 

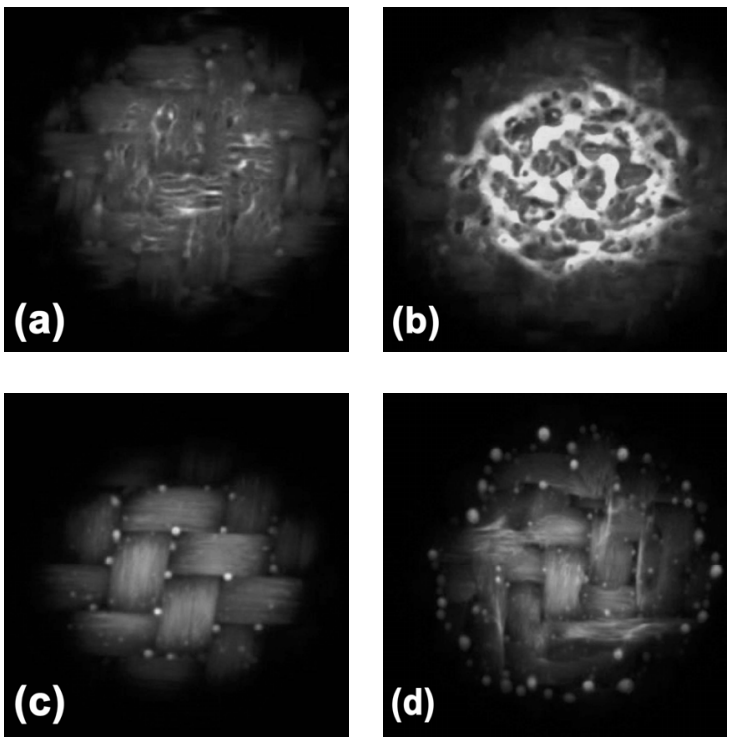

Figure 6. In-ablation area after $1 \mathrm{~s}$ under the torch for SiRC (a) and CRC (c), similar observations after $5 \mathrm{~s}$ of exposure for SiRC (b) and CRC (d).

lation rate is influenced by the thickness of the structure. To evaluate the effect of the sample thickness, the ablation tests were conducted on the SiRC for two different thicknesses (5 and $2.5 \mathrm{~mm}$ ). The corresponding results are presented in Figures $\mathbf{7}$ and $\mathbf{8}$.

The linearity of the mass loss as a function of time is still observed for both types of samples, with a higher mass loss rate for the $2.5 \mathrm{~mm} \mathrm{SiRC}$ composite samples than for the $5 \mathrm{~mm}$ thick. For a half thickness sample, the mass loss rate is approximately 5 times greater.

For the $5 \mathrm{~mm}$ thick SiRC composite samples, it appears that the ablation degradation is non-linear: in the first seconds of exposure, an apparent mass gain and thickness increase are obtained, see Figure 8.

The evaluation of the ablation depth after exposure showed the same general trend. The influence of the initial sample thickness is more significant for the ablation depth than for the mass loss.

After an initial non-linear regime, the ablation behaveior seems to display more or less linear degradation during the exposure. The negative values reported in the first 5 seconds correspond to the void growth and the glass formation observed in the SEM photograph (Figure 5).

\subsection{Influence of Sequence of Exposure}

For exposure time under $5 \mathrm{~s}$, the SiRC reinforced composite showed a mass gain and surface expansion: this is obviously connected with non linear ablative behavior observed in Figures 7 and 8.

A specific test consisting in sequential exposures (ME

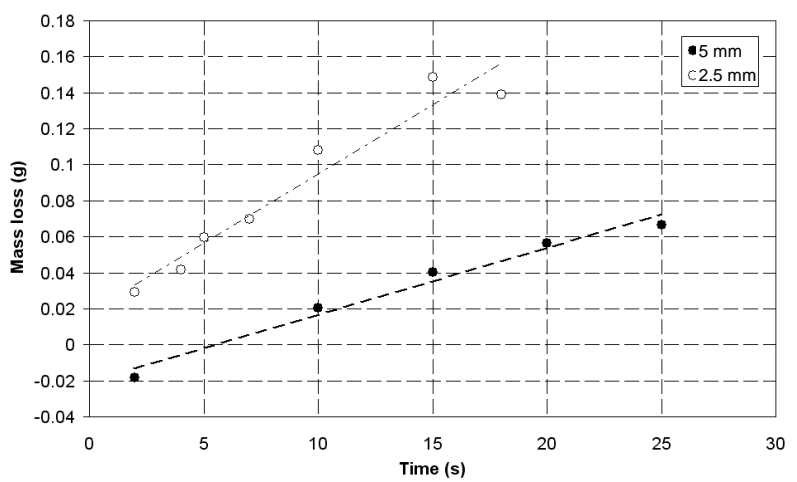

Figure 7. Mass loss for two different SiRC composite thicknesses.

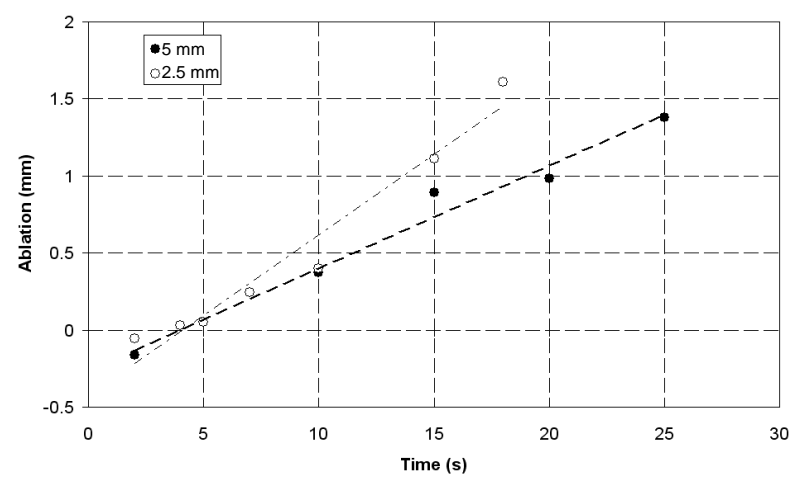

Figure 8. Ablation depth for two different SiRC composites thicknesses.

tests) was then specified to get a better understanding of this phenomenon and of its influence on the ablation properties. Mass loss and ablation depth in case of ME tests are presented in Figures 9 and 10, respectively.

It is observed that when the number of exposure sequences decreases, the ablation depth and mass loss rise up for SiRC while CRC remains almost insensitive to the exposure sequence. It can only be noted a very slight mass loss increase with the sequence length increase for CRC.

For SiRC, there is a link between the number of exposure sequences and the degradation. For many short sequences under hot gases, degradation is smaller than for the same time using one global exposure.

\section{Discussion}

The ablative properties of two composites having the same glass ceramic matrix and the same architecture but different fibers are studied. The nature of fibers has been identified to have a deep impact on the ablation resistance, especially in case of multi-exposures where SiRC exhibits superior ablative properties. 


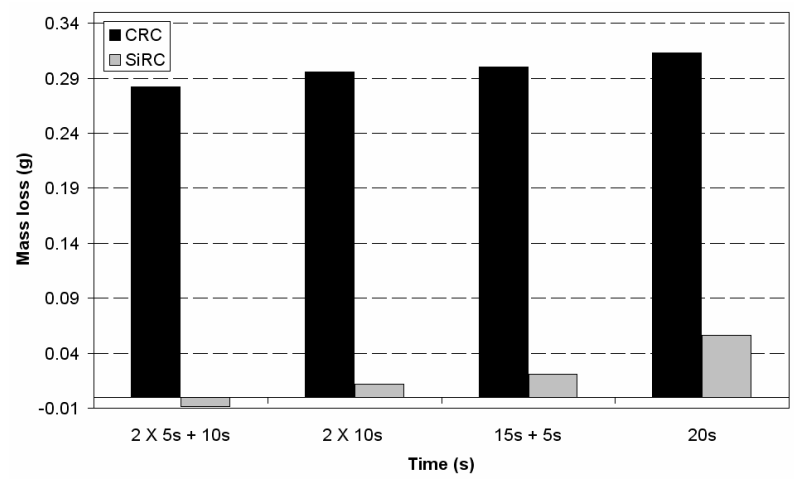

Figure 9. Mass loss of SiRC under multi-exposure sequences for estimating ablation behavior under complex thermal loads.

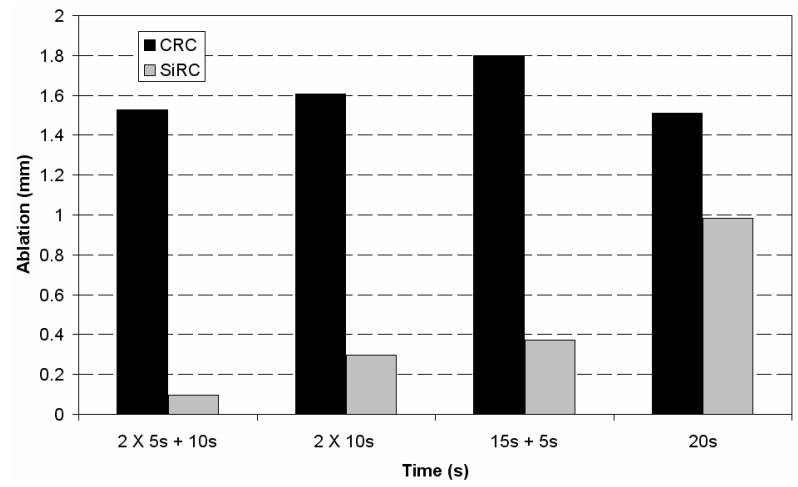

Figure 10. Ablation of SiRC under multi-exposure sequences for estimating ablation behavior under complex thermal loads.

The origin of such differences in ablation resistance is addressed in the first part of the discussion below while the second part is aimed at summarizing the ablation mechanisms of these composites.

\subsection{Differences in Ablation Resistance between SiRC and CRC}

The SiRC composite has been identified to be a better ablator than CRC under $2500 \mathrm{~K}$ oxidative ablation conditions. This result is not obvious based on TGA results which were performed until $1473 \mathrm{~K}$ (Figure 2).

In fact, both materials exhibit a very similar mass loss behavior in the investigated TGA temperature range, except for the highest temperatures $(\mathrm{T}>1300 \mathrm{~K})$ where the $\mathrm{SiRC}$ was found to have a higher mass rate increase compared to CRC. It is therefore clear that the difference in ablative resistance of both materials arises from chemical reactions encountered in the $1300-2500 \mathrm{~K}$ range, and especially, the oxidation of the materials compounds.

Many authors reported that for high temperature and oxidative conditions, the solid carbon begins to react with oxygen at $800 \mathrm{~K}$. Many other species interact with solid carbon during exposure with the following chemical reactions [2]:

$$
\begin{gathered}
\mathrm{H}_{2} \mathrm{O}_{(\mathrm{g})}+\mathrm{C}_{(\mathrm{s})} \rightarrow \mathrm{H}_{2(\mathrm{~g})}+\mathrm{CO}_{(\mathrm{g})} \\
\mathrm{CO}_{2(\mathrm{~g})}+\mathrm{C}_{(\mathrm{s})} \rightarrow 2 \mathrm{CO}_{(\mathrm{g})} \\
\mathrm{H}_{2(\mathrm{~g})}+2 \mathrm{C}_{(\mathrm{s})} \rightarrow \mathrm{C}_{2} \mathrm{H}_{2(\mathrm{~g})} \\
\mathrm{O}_{2(\mathrm{~g})}+2 \mathrm{C}_{(\mathrm{s})} \rightarrow 2 \mathrm{CO}_{(\mathrm{g})} \\
\mathrm{OH}_{(\mathrm{g})}+\mathrm{C}_{(\mathrm{s})} \rightarrow 1 / 2 \mathrm{H}_{2(\mathrm{~g})}+\mathrm{CO}_{(\mathrm{g})} \\
\mathrm{H}+\mathrm{C}_{(\mathrm{s})} \rightarrow 1 / 2 \mathrm{C}_{2} \mathrm{H}_{2(\mathrm{~g})} \\
\mathrm{O}+\mathrm{C}_{(\mathrm{s})} \rightarrow \mathrm{CO}_{(\mathrm{g})}
\end{gathered}
$$

The $\mathrm{SiC}$ based composites exhibit a better oxidation resistance compared to the carbon reinforced composites since, as it has been shown, the $\mathrm{SiC}$ reacts with oxygen to form a protective $\mathrm{SiO}_{2}$ glass film at the top surface of the material and in the interbundle pores [3]. $\mathrm{SiO}_{2}$ is a well known effective diffusion barrier against the inward diffusion of oxygen. When surface temperature is close to $2000 \mathrm{~K}$, liquid $\mathrm{SiO}_{2}$ flows and plugs the cracks and pores in the surface, thus providing a sufficient oxidation protection due to its very low oxygen diffusivity, reported to be $3.5 \times 10^{-14} \mathrm{~m}^{2} \cdot \mathrm{s}^{-1}$ in literature [5].

In our experiments, the $\mathrm{SiO}_{2}$ liquid phase is clearly observed during ablation (Figure 6(b)). This mixture is only observed at the top surface of the SiRC due to the decomposition of fibers while $\mathrm{CRC}$ exhibits $\mathrm{Si}$ rich droplets (evidenced by EDX measurements not shown here) produced by the glass matrix decomposition.

Another interesting point regarding the beneficial effect of the $\mathrm{SiC}$ degradation into a $\mathrm{SiO}_{2}$ liquid film is obtained for short timespan exposures at $2500 \mathrm{~K}(\mathrm{t}<5 \mathrm{~s})$. A mass gain and a thickness increase are observed due to $\mathrm{SiO}_{2}$ film formation (Figures 3 and 4). Biamino [4] described this mass gain $/ \mathrm{mol}$ as $50 \% \mathrm{~mol}$. $\left(40.10 \mathrm{~g} \cdot \mathrm{mol}^{-1}\right.$ $\mathrm{SiC}$ and $60.08 \mathrm{~g} \cdot \mathrm{mol}^{-1} \mathrm{SiO}_{2}$ ) which overcompensates the mass losses due to CO release by Equations (1), (2), (4), (5), (7). In this case the overall procedure is called "passive oxidation" of the $\mathrm{SiC}$ composite. If the oxygen reaches the silicon carbide fibers through cracks or because of the failure of the protective layer, then the overall procedure is called "active oxidation" of the SiRC and is followed by a mass reduction of the sample [17].

For short exposure time of SiRC, mass measurements provide evidence for this hypothesis while for longer exposure, the heat and oxygen species released by oxyacetylene torch diffuse through the composite and the active oxidation begins (exposure time $>5 \mathrm{~s}$ ). The reaction 
below shows the $\mathrm{SiO}_{2}$ formation $[4,8,10]$ :

$$
2 \mathrm{SiC}+3 \mathrm{O}_{2} \rightarrow 2 \mathrm{SiO}_{2(1)}+2 \mathrm{CO}_{(\mathrm{g})}
$$

The $\mathrm{SiO}_{2}$ film is beneficial for all the investigated $\mathrm{SE}$ conditions probably due to the above mentioned low oxygen diffusivity of $\mathrm{SiO}_{2(1)}$ but the most spectacular effect of the $\mathrm{SiO}_{2}$ formation is observed in our experiments in case of multi-exposures (ME) tests.

For a given total ablative time of $20 \mathrm{~s}$, an increase in the number of torch exposure sequences (i.e. a decrease of the average exposure time) leads to an ablation depth which can be divided by 10 (Figure 10) and dwindling in mass loss, reaching even a mass gain (Figure 9). In contrast with the SiRC the CRC composite behavior remains almost unaffected by the ablation sequence under the investigated conditions. This much more pronounced effect of the $\mathrm{SiO}_{2}$ film formation in $\mathrm{ME}$ experiments compared to $\mathrm{SE}$ tests can be explained by the $\mathrm{SiO}_{2(1)} \rightarrow$ $\mathrm{SiO}_{2(\mathrm{~s})}$ transformation upon cooling between exposures and the $\mathrm{SiO}_{2(\mathrm{~s})} \rightarrow \mathrm{SiO}_{2(1)}$ transformation upon re-heating.

In fact, $\mathrm{SiO}_{2(\mathrm{~s})}$ is an even more efficient diffusion barrier and the solid $\rightarrow$ liquid phase change (at $\mathrm{T} \approx 1750 \mathrm{~K}$ $\pm 75 \mathrm{~K}[18]$ ) is endothermic, thus, leading to a reduced net heat flow received by the material and finally to a reduced ablation.

\subsection{Degradation Mechanisms}

The experiments performed in this study allow us to propose a scenario of the degradation mechanisms for the SiRC composite (Figure 11).

Once the material is exposed to hot gases $(\mathrm{T} \approx 3000 \mathrm{~K})$ the impacted area is instantaneously heated. The $\mathrm{SiC}$ reacts with the hot oxidative gases. $\mathrm{SiO}_{2}$ appears resulting from $\mathrm{SiC}$ oxidation. A capillarity mechanism leads to produce liquid $\mathrm{SiO}_{2}$ in impacted area. Voids appear in the resulting volume (volumetric ablation). This phase change is endothermic. A part of the inflow is absorbed by this reaction. Fused $\mathrm{SiO}_{2}$ protects from the oxidation and absorbs energy. This is the first step of ablation: the passive oxidation.

The second step begins when the $\mathrm{SiO}_{2}$ temperature rises to the vaporization threshold. On the one hand the heat is driven in the bulk and on the other hand, fibers begin to react with hot gases and the material loses mass. Upon cooling, $\mathrm{SiO}_{2}$ is solidified to form an amorphous glass.

Figures 7 and 8 show the effects of different thicknesses for the SiRC composite. The mass loss is clearly influenced by the size of the samples. These results confirm the analysis of Staggs [16]. For a thinner sample, the influence of thermal resistance of air in rear face is more effective. The heat is trapped in the material due to the low thermal coefficient of natural convection in rear face. The heat flow conduction is strongly limited. As a result, the local temperature increases rapidly. The degradation occurs in a shorter time than for a thick material with high diffusion ability. For a thin plate, the instantaneous heating leads earlier to active oxidation than for a thick one.

The last kind of test conducted is ME (multi-exposures) test. Degradation decreases with an increase of the number of exposure stages. For a short exposure period, a passive oxidation produces an amorphous solid glass during cooling. This glass has a high melting point and so, during the subsequent torch exposure, the material is protected by this $\mathrm{SiO}_{2}$ coating. For the same number of stages, degradation is driven by a time of the longest exposure. A longer time under the torch produces a larger heat-affected zone and so, a larger reaction zone with oxidative species.

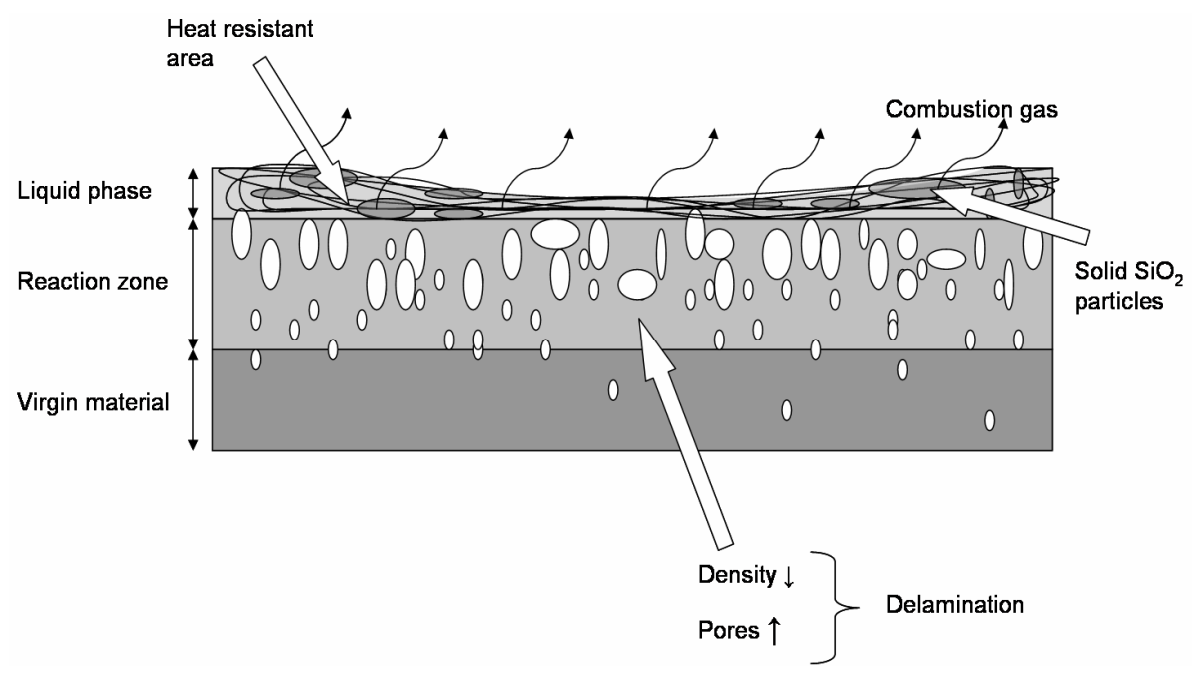

Figure 11. Degradation mechanisms of SiRC composite during ablation. 


\section{Conclusions}

The carbon-reinforced glass ceramic matrix composite exhibits a poorer ablation resistance under oxyacetylene torch compared to the $\mathrm{SiC}$ reinforced one. This superior ablation resistance of $\mathrm{SiC}$ glass ceramic matrix has been evidenced for either of torch exposure tests (simple and sequential) where the difference between both materials is even enhanced. This superior ablation resistance of glass ceramic matrix/SiC composite results from the formation of an $\mathrm{SiO}_{2}$ liquid film whose melting is endothermic at temperature above $1600 \mathrm{~K}$, hence reducing the net heat flow received by the in-situ $\mathrm{SiO}_{2}$ coated composite.

\section{Acknowledgements}

The authors gratefully acknowledged Christelle Roudault (LACCO, UMR CNRS 6503) for her help in the TGA experiments. Thanks to Damien Marchand for technical support.

\section{REFERENCES}

[1] D. E. Glass, "Ceramic Matrix Composite (CMC) Thermal Protection Systems (TPS) and Hot Structures for Hypersonic Vehicles," 15th AIAA Space Planes and Hypersonic Systems and Technologies Conference, Dayton, 28 April1 May 2008, pp. 1-36.

[2] B. Chen, L. T. Zhang, L. F. Cheng and X. G. Luan, "Ablation of Pierced C/C Composite Nozzles in an Oxygen/ Ethanol Combustion Gas Generator," Carbon, Vol. 47, No. 3, 2009, pp. 291-293. doi:10.1016/j.carbon.2008.10.009

[3] Y. J. Lee and H. J. Joo," Ablation Characteristics of Carbon Fiber Reinforced Carbon (CFRC) Composites in the Presence of Silicon Carbide (SiC) Coating," Surface \& Coatings Technology,Vol. 180-181, 2004, pp. 289-289. doi:10.1016/j.surfcoat.2003.10.071

[4] S. Biamino, V. Liedtke, C. Badini, G. Euchberger, I. H. Olivares, M. Pavese and P. Fino, "Multilayer SiC for Thermal Protection System of Space Vehicles: Manufacturing and Testing under Simulated Re-Entry Conditions," Journal of the European Ceramic Society, Vol. 28, No. 14, 2008, pp. 2791-2800. doi:10.1016/j.jeurceramsoc.2008.04.006

[5] A. R. Bahramian, M. Kokabi, M. H. N. Famili and M. H. Beheshty, "Ablation and Thermal Degradation Behaviour of a Composite Based on Resol Type Phenolic Resin: Process Modeling and Experimental," Polymer, Vol. 47, No. 10, 2006, pp. 3661-3673. doi:10.1016/j.polymer.2006.03.049

[6] M. P. Bacos, "Carbon-Carbon Composites - Oxidation Behavior and Coatings Protection," Journal de Physique Archives, Vol. 3, No. C7, 1993, pp. 1895-1903. doi:10.1051/jp4:19937303
[7] S. F. Tang, J. Y. Deng, S. J. Wang and W. C. Liu, "Comparison of Thermal and Ablation Behaviors of $\mathrm{C} / \mathrm{SiC}$ Composites and $\mathrm{C} / \mathrm{ZrB}_{2}-\mathrm{SiC}$ Composites," Corrosion Science, Vol. 51, No. 1, 2009, pp. 54-61.

doi:10.1016/j.corsci.2008.09.037

[8] B. Yan, Z. F. Chen, J. X. Zhu, J. Z. Zhang and Y. Jiang, "Effects of Ablation at Different Regions in Three-Dimensional Orthogonal C/SiC Composites Ablated by Oxyacetylene Torch at $1800^{\circ} \mathrm{C}, "$ Journal of Materials Processing Technology, Vol. 209, No. 7, 2009, pp 3438-3443.

[9] Z. Chen, D. Fang and B. Yan, "Comparison of Morphology and Microstructure of Ablation Centre of $\mathrm{C} / \mathrm{SiC}$ Composites by Oxy-Acetylene Torch at $2900^{\circ} \mathrm{C}$ and $3550^{\circ} \mathrm{C}$," Corrosion Science, Vol. 50, No. 12, 2008, pp. 3378-3381. doi:10.1016/j.corsci.2008.07.019

[10] D. Fang, Z. Chen, Y. Song and Z. Sun, "Morphology and Microstructure of 2.5 Dimension C/SiC Composites Ablated by Oxyacetylene Torch," Ceramic International, Vol. 35, No. 3, 2009, pp. 1249-1253. doi:10.1016/j.ceramint.2008.06.008

[11] M. Hussain, R. J. Varley, Y. B. Cheng and G. P. Simon, "Investigation of Thermal and Fire Performance of Novel Hybrid Geopolymer Composites," Journal of Material Science, Vol. 39, No. 14, 2004, pp. 4721-4726. doi:10.1023/B:JMSC.0000034180.35216.ba

[12] A. C. J. Flowerday, P. N. H. Wright, R. O. Ledger and A. G. Gibson, "Investigation into the Use of Geopolymers for Fire Resistant Marine Composites," Advanced Marine Materials and Coatings International Conference, London, 22-23 February 2006, pp. 37-44.

[13] C. Buchler and M. Rollin, "User-Friendly Composites That Take the Heat," JEC Composites Magazine, Vol. 53, 2009, pp. 33-35.

[14] G. Pulci, J. Tirillo, F. Marra, F. Fossati, C. Bartuli and T. Valente, "Carbon-Phenolic Ablative Materials for Re-Entry Space Vehicles: Manufacturing and Properties," Composites Part A: Applied Science and Manufacturing, Vol. 41, No. 10, 2010, pp. 1483-1490.

[15] Y. I. Dimitrienko, "Thermomechanical Behaviour of Composite Materials and Structures under High Temperatures: 1," Composites Part A: Applied Science and Manufacturing, Vol. 28, No. 5, 1997, pp. 453-461.

[16] J. E. J. Staggs, “A Discussion of Modelling Idealised Ablative Materials with Particular Reference to Fire Testing," Fire Safety Journal, Vol. 28, No. 1, 1997, pp. 44-66. doi:10.1016/S0379-7112(96)00062-8

[17] C. Argirusis, T. Damjanovic and G. Borchardt, "Yttrium Silicate Coating System for Oxidation Protection of C/C-Si-SiC Composites: Electrophoretic Deposition and Oxygen Self-Diffusion Measurements," Fire Safety Journal, Vol. 27, No. 2-3, 2007, pp. 1303-1306.

[18] W. L. Vaughn and H. G. Maahs, "Active-to-Passive Transition in the Oxidation of Silicon-Carbide and Silicon- Nitride in Air," Journal of the American Ceramic Society, Vol. 73, No. 6, 1993, pp. 1540-1543. doi:10.1111/j.1151-2916.1990.tb09793.x 